\title{
Kurtide folkloori kogumine, uurimine ja õpetamine
}

\begin{abstract}
Liina Paales
Teesid: Artiklis vaadeldakse kuulmisvõimetuse kui inimliku mitmekesisuse folkloristlikku uurimist. Keskendutakse autori kui kuulja kogemusele eesti kurtide folkloori kogumisel, uurimisel ja õpetamisel. Uudse kogumiskeskkonnana käsitletakse Facebooki gruppi "Eesti kurtide folkloor", mille algatas kurt isik ja mis on kogukonna ja eesti viipekeele keskne. Viipekeelsed folklooritekstid, mis ühtlasi jäädvustavad visuaalset keelt ja peegeldavad kogukonna eneseteadvust, on vajalikud nii uurimistöös kui ka erialaspetsialistide väljaõppes. Sotsiaalmeedia võimaldab küll eesti viipekeelset tekstiloomet ja kurtide pärimuse kogumist, ent samas kaasnevad nii grupi administreerimise kui ka videopostituste käsitlemisega mitmed kogumisspetsiifilised, eetilised ja õiguslikud küsimused.
\end{abstract}

Märksõnad: eesti viipekeel, Facebook, folkloristika, kurdid, kurdiksolemine

Kuulmisvõimetuse eri aspektidega tegeldakse mitme teadusala raames. Ilmselgelt tegelevad kurtuse kui patoloogiaga arstiteadlased, kuulmispuudelisi puudutavate õiguslike küsimustega juristid, viipekeele uurimisega lingvistid, kuulmispuudega laste õpetamisega pedagoogid või eripedagoogid ja kurtusest tingitud psühholoogiliste eripäradega psühholoogid.

Käesolevas artiklis keskendutakse kurtide rahvarühmale, kitsamalt Eesti kurtide kogukonnale ja selle kultuurile folkloristika vaatepunktist. Vaadeldakse rahvaluuleteaduse võimalusi kuulmisvõimetuse ja kurdiksolemise uurimisel ning saadud teadmiste rakendamisel.

\section{Kuulmisvõimetus ja kurdiksolemine}

Kõrvaarstid diagnoosivad kuulmislanguse, geeniteadlased uurivad kurtust põhjustavaid, muteerunud geene ${ }^{1}$ ja biotehnoloogid arendavad kuuldetehni- 
kat. Kaugem eesmärk on kurtusest jagusaamine. Võimalik, et tulevikus see ka õnnestub. Õiguslikke küsimusi, nagu (kuulmis)puudest tulenev diskrimineerimine, aga ka kurtide keelelised ja kultuurilised õigused, vaevad juristid. Meditsiini- ja sotsiaalhoolekande süsteemis on märksõnadeks sekkumine, ravimine, küborgiseerimine ${ }^{2}$ ja rehabiliteerimine. Loodetavaks tulemuseks haridussüsteemi kaasabil on võimalikult hea kõne- ja kirjutamisoskusega iseseisvalt toimetuleva kuuljapärase isiku disainimine. Üks võimalusi on suhelda kuuljatega viipekeeletõlgi ${ }^{3}$ vahendusel, mis annab viipekeelsele inimesele asjaajamisel, hariduse omandamisel, kultuuri tarbimisel ja muudes situatsioonides iseseisvuse ja keelelise võrdsuse. Selle saavutamine aga sõltub tõlketeenuse kättesaadavusest, mahust ja tõlkide professionaalsusest.

Inimmõtlemisele omased binaarsed opositsioonid on omal kohal ka käesoleva teema puhul. ${ }^{4}$ Kultuuriteadusteski on fookuses kurt keha, kuid mitte diagnoositava ja mõõdetava objektina, vaid selle kehastunud kogemused, keele, kultuuri ja identiteedi küsimused. Kuulmisvõimetust või kuulmispuuet käsitatakse siinkohal inimliku mitmekesisusena. Igapäevaselt on kurdiksolemine $^{5}$ loomulikult väljakutse: kuulmisvõimetul tuleb silmitsi seista piiratud toimetuleku-, suhtlemis-, haridus- ja töövõimalustega kuulmisele ja suulistele keeltele rajatud ühiskonnas. Tuleb tunnistada, et mitmed kuuljate kurtuse ja viipekeelega seotud hoiakud tulenevad nii mõnigi kord alusetutest ja argistest väärarvamustest. ${ }^{6}$

\section{Kurtide rahvarühm}

Kes on kurdid sotsiaalse rühmana? Uurijad on määratlenud neid nii etnose (Deaf ethnos / Deafnicity), rahvuse (Deaf nation) kui rassi (Deafrace) järgi (vt Delaporte 2002; Uhlig 2012; Eckhert 2010); aga ka kui puudega inimesi (Davis 2008) või keele- ja kultuurivähemusi (Batterbury \& Ladd \& Gulliver 2007).

Käesolevas artiklis lähtutakse Ameerika folkloristi Alan Dundese rahvarühmade käsitlusest. ${ }^{7}$ Rahvarühma mõiste võimaldab jätta lahtiseks, kas tegemist on vähemuse, etnose, puudeliste või muud laadi grupiga (vt ka Rutherford 1993). Alan Dundese sõnul ületaks mõiste rahvas kasutamine etnilise rühma piirid. Tänapäevase rahva määratluse kohaselt võib üksikisik kuuluda samaaegselt mitmesse eri rühma, olgu see siis perekond, rahvus, etniline, usuline või ametialane rühm. Siiski peab eri rühmade vahel liikudes valdama koodivahetust. Mitmesse rühma kuulumine võimaldab vahetada identiteeti ja sobiva identiteedi valikuvabadust (Dundes 2002: 44, 48).

Kurtide rühmaidentiteedi piiritlemisel peetakse rühma liikmete puhul silmas mitmeid samasuse ilminguid, milleks on kurdiksolemine, viipekeeleoskus 
ja kurtide kultuuri tundmine. Konkreetse lokaalse kurtide rühma puhul kasutan kogukonna või koosluse mõistet.

\section{Eesti kurtide kogukond ja eesti viipekeel}

Statistilise näitaja kohaselt on kurte inimesi rahvastikust $0,1 \%$. Tuhande elaniku kohta sünnib või kurdistub varases lapseeas 1-4 isikut (Councile of Europe 2003, viidatud Matthews \& McKee \& McKee 2009: 721). 2011. aasta rahvaloenduse andmeil oli Eestis elanike arv 1,3 miljonit inimest, neist kurte peaks olema ligikaudu 1300. Eesti viipekeele kui emakeele kasutajaid on vähem. Viimasel rahvaloendusel oli eesti viipekeele emakeeleks märkinud 148, vene viipekeele 21 inimest (Eesti Statistikaamet). Koos kurtide pereliikmete, sugulaste, sõprade, õpetajate ja teiste keelevaldajatega arvatakse eesti viipekeele regulaarseid kasutajaid olevat umbes 4500 (Laiapea et al. 2003: 28).

Eestis sünnib 1000 vastsündinud kohta üks-kaks kurti, aastas ligikaudu 15 last. Suurem osa kurte lapsi sünnib kuuljate perre. Neile paigaldatakse implantaat ja nad asuvad õppima tavakooli. Kultuurilisest vaatenurgast kasvavad need kurdid lapsed kuuljateks. Nad assimileeruvad eesti keele kõnelejaina enamuskogukonda. Üldjoontes eesti viipekeelt valdavate kurtide arvukus väheneb, samal ajal on kuuljate hulgas eesti viipekeele õppimine jätkuvalt populaarne.

Eesti viipekeel on kogukondliku taustaga visuaal-motoorne keel. Selle tekkimist on seostatud kurtide kooli rajamisega Vändrasse 1866. aastal, kuid kurtide koolid tegutsesid lühemat aega ka Saaremaal ja Põlvas. Esialgu jäi viiplemine vaid rühmasiseseks suhtlusviisiks. Kurtide kooli lõpetanult, kes oli õppinud suulise meetodi ${ }^{8}$ järgi nii kõnelema kui kirjutama, oodati kuuljatega suhtlemist eesti keeles nii kõnes kui ka kirjas. Koolitamata kurttummasid aitasid vahendada viiplemisoskusega lähedased või tuttavad. 1950. aastatel loodi esimesed ametikohad viipekeeletõlkidele - tookord nimetati neid küll miimikatõlkideks (Toom 2002: 62).

Viiplemist aktsepteeriti õpetaja ja õpilase omavahelises suhtluses 1980. aastate lõpul Porkuni kurtide koolis. Kakskeelse õpetamismetoodikaga tunnustati viiplemist alates 1990. aastate algusest viimaks ka kurtidele hariduse andmisel - seda nimelt Tallinna Heleni Koolis (varasem nimetus Tallinna Kurtide Kool), mis alustas tööd 1994. aastal. Eesti viipekeelt tunnustati keeleseaduses 2007. aastal. Viipekeeletõlgi vahendusel suheldakse eesti viipekeeles ka kuuljatega. Välja on antud eesti viipekeele aabits (Paabo 2011) ja käsiraamat eesti viipekeele õppimiseks (Paabo 2010). Olemas on veebipõhine eesti viipekeele ja eesti keele sõnastik, eesti viipekeel on esindatud rahvusvahelises viipekeelte sõnastikus "Spreadthesign: Sign Language Dictionary" ning koostatud on ka eesti viipekeele ja rahvusvahelise viiplemise e-sõnastik. 


\section{Kurtide rahvaluule kogumisest, uurimisest ja õpetamisest välismaal}

Nii nagu algas Ameerika Ühendriikides 1960. aastatel kurtide viipekeelte William C. Stokoe käsitles nimelt ameerika viipekeelt - keeleteaduslik uurimine, sai seal 1970. aastatel alguse ka kurtide folkloori kogumine ja uurimine. Selle algataja on kurt antropoloog Simon J. Carmel. Tema sõnastas ka esimese kurtide rahvaluule definitsiooni, mille järgi on tegemist kuulmisvõimetute inimeste - unikaalse keele- ja kultuurivähemuse - pärimusega, millel on mitmeid liike ja mida edastatakse ühelt põlvkonnalt järgmisele põlvkonnale viipekeele vahendusel (Carmel 1996: 198-199). Sellele lisaks on uuritud ka briti, prantsuse ja saksa kurtide folkloori. Enamjaolt on uurijad olnud viipekeelt valdavad kuuljad, sekka üksikud kurdid (vt Paales 2011: 47-49).

Kui kasutada interneti lihtotsingut, võib näha, et kurtide folkloori ainekursust õpetatakse rahvusvahelises kontekstis mõnes kõrgkoolis seoses viipekeeletõlkide koolitamise või kurtide uuringute (Deaf studies) suunal. (Kahjuks ei ole andmeid kurtide folkloori õpetamise kohta Eesti naaberriikides.) Nimetuse all Deaf Literature and ASL Folklore või Deaf Literature õpetatakse seda Ameerika Ühendriikides näiteks Bostoni ülikoolis kurtide uuringute programmis, California riiklikus Northrige'i ülikoolis (CSUN) (Deaf Literature) ja Massachusettsi kolledžis. ${ }^{9}$ Kurtide folkoori tutvustamise ja kogumise propageerijana tegutseb jätkuvalt Simon J. Carmel, kes korraldab eri riikides selleteemalisi töötubasid ja seminare.

\section{Eesti kurtide folkloori kogumisest, uurimisest ja õpetamisest isikliku kogemusena}

Siinkirjutaja, kellel endal on kuulja taust ja päritolu ning enne ülikooliõpinguid puudusid igasugused varasemad kokkupuuted kurtide ja viipekeelega, hakkas kurtide folklooriga tegelema 1990. aastate keskel. Algtasemel keeleoskus oli võimalik omandada Tartu Ülikooli eripedagoogika osakonna ainekursustel "Viipekommunikatsioon I" ja "Viipekommunikatsioon II" (1993-1994), mida sai eesti filoloogia bakalaureuseõppes võtta valikkursustena. ${ }^{10}$ Keeleoskus süvenes edasises kokkupuutes kurtide kogukonna liikmetega nii isiklikul tasandil kui ka ametialases sfääris viipekeeletõlgi ja kuulmispuudega õpilaste eesti keele õpetajana. Kurtide seltskonnas tabanud äratundmine, et teatud tekstide puhul on tegemist elava rahvaluulega, viis mind teoreetiliste käsitluste otsingule. Siit sai tõuke huvi kurte kui kultuurirühma käsitleva inglis-, saksa- ja prantsuskeelse kirjanduse vastu. 
Bakalaureusetöö kirjutasin eesti kirjanduse alalt, ent juba magistritöö teemaks sai Eesti kurtide pärimus. Magistriuurimuse raames tehtud kurtide folkloori kogumine oli toona üsna algeline. Informantidelt (peamiselt Porkuni Kurtide Kooli vilistlased) küsisin eesti viipekeeles suunavaid küsimusi erinevate folklooriliikide kohta ning lasin viibelda vabalt anekdoote, kogemuslugusid, mälestusi, keelemänge ja viipenimesid. Kõige suuremaks puuduseks oli see, et viipetekstid jäid toona algupärases esituses üles filmimata. Need panin kirja eestikeelses tõlkes kohapeal või siis hiljem märkmete põhjal ja mälu järgi. Eelkirjeldatud tõlketekstid sisalduvad magistritöö lisas (Paales 2000: 188-219) ja seda folkloorikogu säilitatakse Eesti Rahvaluule Arhiivis (EFA I, 47).

Oluline sündmus nii Eesti kurtidele kui ka folkloristikale oli Ameerika kurdi antropoloogi ja folkloristi Simon J. Carmeli esinemine Tartu Ülikoolis eesti ja võrdleva rahvaluule osakonnas 2006. aastal seminaril "Viipekeelsete inimeste kultuur ja folkloor”. ${ }^{11}$ Kokkuvõtvalt võib öelda, et eesti kurtide folklooriga tegelemise algus oli kogemuspõhine.

Eripedagoogika erialast on alguse saanud nii eesti viipekeele õpetamine kui ka hilisem viipekeeletõlkide koolitamine. Tartu Ülikooli haridus- ja sotsiaalteaduste instituudi eripedagoogika osakonnas avati eesti viipekeele tõlgi õppekava 2006. aastal. Nimetatud õppekavas on alates algusest peale kuni tänaseni olnud ka kursused "Kurtide folkloor" ja "Kurtide kultuur".

Ainekursuse "Kurtide folkloor" ettevalmistamisel salvestati mitmed viipetekstid. ${ }^{12}$ Aluseks võeti eelmainitud magistritöö raames loodud folkloorikogu (EFA I, 47). Nüüd taasesitati seesama materjal eesti viipekeeles. Seega ei ole need viipekeelde tagasi tõlgitud tekstid autentsed (elavad), tegemist on õppeotstarbelise lavastusliku esitusega. Ühtlasi puuduvad videotekstidel subtiitrid.

Ülikoolisiseste ümberkorralduste tulemusel toimub alates 2016. aastast õppetöö neljas valdkonnas, milleks on humanitaarteaduste ja kunstide valdkond, sotsiaalteaduste valdkond, meditsiiniteaduste valdkond, loodus- ja täppisteaduste valdkond. Aktuaalne küsimus on, mis valdkonnas võiks õpetada selliseid kurtide rahvarühmaga seotud aineid nagu "Kurtide folkloor" ja "Kurtide kultuur", mis mõlemad on tihedalt seotud ka viipekeelega? ${ }^{13}$

Hetkel on kujunenud olukord nii, et eesti viipekeelt teise keelena on võimalik Tartu Ülikoolis õppida kahes valdkonnas. Üleülikoolilise vabaainena õpetatakse seda alates 2011/2012. õppeaastast humanitaarteaduste ja kunstide valdkonnas maailma keelte ja kultuuride kolledžis Balti regiooni keelte all ("Eesti viipekeele algkursus", "Eesti viipekeele jätkukursus"). ${ }^{14}$ Loomulikult sisaldub eesti viipekeel õppeainena eesti viipekeeletõlgi õppekavas (mis kuulub humanitaaria ja kunstide valdkonda) ja traditsioonipõhiselt eripedagoogika õppekavas (sotsiaalteaduste valdkond). Mõlemat õppekava haldab sotsiaalteaduste valdkonnas haridusteaduste instituut. Siinkirjutaja arusaama kohaselt olekski loomulik edaspidi õpetada eesti viipekeelt kui üht visuaal-motoorset 
keelt kõrvuti suuliste keelte ja eesti viipekeele tõlke koos suuliste keelte tõlkidega. Kurtide rahvarühma kultuuri ja folkloori õpetamine võiks olla seotud aga rahvaluule õppekavaga. Tulevikuperspektiivis võiks olla rahvaluulehuviliste kurtide koolitamine.

\section{Rahvaluule mõisted eesti keeles ja eesti viipekeeles}

Selleks, et hakata kirjeldama eesti kurtide folkloori, oli vaja eestikeelset mõistevara. Kurtide rahvaluulega seotud mõistete loomist mõjutas valdavalt ingliskeelne erialakirjandus. Kõige keerulisem oli leida nimetusi mõne viipekeelespetsiifilise folklooriliigi tarbeks (vt lähemalt Paales 2001). Järgnevalt mõned näited mõisteloomest mõlemal keelesuunal.

Eestikeelsete mõistete puhul on eristatavad rühma- ja keeletasand. Mõisteühendite puhul nagu kurtide folkloor, kurtide pärimus, kurtide rahvaluule tekib kokkupuutepunkte muude rühmade pärimusega. Kommunikatiivsetele eripäradele nagu nägemis- ja liigutuspõhisus (visuaal-motoorne), pantomiimilisus ja miimilisus osutavad viipekeelne folkloor, viipekeelne pärimus, viipekeelne rahvaluule (Paales 2001: 131).

Rahvaluulealased mõisted loodi ja salvestati koostöös kurtidega ainekursuse "Kurtide folkloor" ettevalmistamisel. ${ }^{15}$ Viipekeelse mõistevara võib jagada kolmeks teemarühmaks: 1) kultuuriteadused, uurijad ja mõned üldmõisted; 2) folklooriliikide nimetused; 3) mõnede rahvaluulega tegelevate kohalike asutuste viipenimed.

Eesti viipekeeles puudus üldse viibe rahvaluule kui nähtuse tähistamiseks. Videosalvestati kaks viibet. Esimene on eestikeelse mõiste tõlkevaste - INIMESED + VÄJAMÕELDIS/FANTAASIA ${ }^{16}$ ). Teine, laenviibe FOLKLORE ameerika viipekeelest, on inspireeritud Simon J. Carmeli esinemisest Tartu Ülikoolis.

I. Kultuuriteaduste, uurijate ja mõned üldmõistete viiped (9): etnoloogia (ETHNOLOGIE) ${ }^{17}$, etnoloog (ETHNOLOGIE + UURIMINE + INIMENE), folkloristika (FOLKLORE ${ }^{18}$ + TEADUS), folklorist (FOKLORE + UURIMINE + INIMENE), pärimus, rahvaluule (INIMESED + VÄLJAMÕELDIS/FANTAASIA), kultuur, kultuuriteadus (KULTUUR + TEADUS), uurimine.

II. Folklooriliikide nimetused (15): anekdoot (FANTAASIA, VÄLJAMÕELDIS), elulugu (ELU + JUTT), jutt (JUTUSTAMA, RÄÄKIMA, KÕNE ${ }^{19}$ ), keelemäng (KEEL + MÄNGIMA), kohamärk (KOHT + OMA + VIIBE), kohapärimus $(\mathrm{KOHAD}+\mathrm{PÄRIMUS})$, kohaviibe $\left(\mathrm{KOHT}+\mathrm{OMA}+\mathrm{VIIBE}+\mathrm{PILT}^{20}\right)$, muinas jutt (MÄNG) ${ }^{21}$, mõistatus (MÕTLEMA + NUPUTAMA), mäng ${ }^{22}$, nimepärimus (NIMI + PÄRIMUS), laul (LAUL), viipenimi ${ }^{23}$ (VIIPLEMA + PILT), isikumärk (INIMENE + OMA + VIIBE), viipemäng (VIIBE + MÄNG). 
Joonis 1. ETNOLOOGIA - laen prantsuse viipekeelest (LSF).
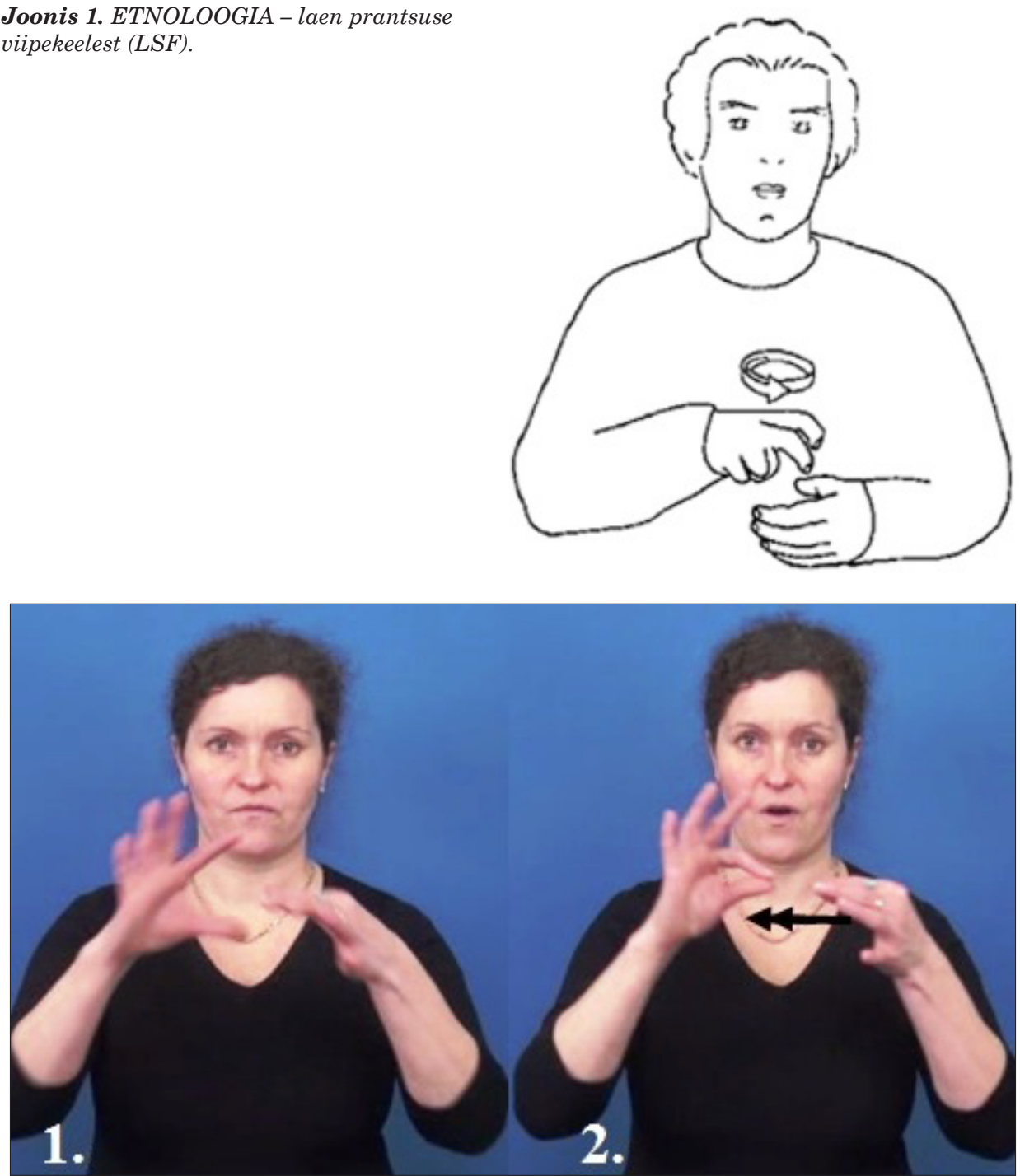

Joonis 2. FOLKLOOR - laen ameerika viipekeelest (ASL).

III. Rahvaluule kogumise, uurimise ja õpetamisega tegelevate asutuste nimetused (3): Eesti Rahvaluule Arhiiv (EESTI + INIMESED + FANTAASIA + ARHIIV/RAAMATUKOGU) Eesti Rahva Muuseum (EESTI + INIMESED + MUUSEUM), kultuuriteaduste ja kunstide instituut (KULTUUR + TEADUS + KUNST + ERINEVAD/MITMESUGUSED + INSTITUUT/ÜLIKOOL). Nimetatud valdkonna viipekeelsete mõistete paremaks kinnistamiseks ja levikuks võiks need olla vaadeldavad asjaomaste asutuste kodulehekülgedel vastavas rubriigis. 


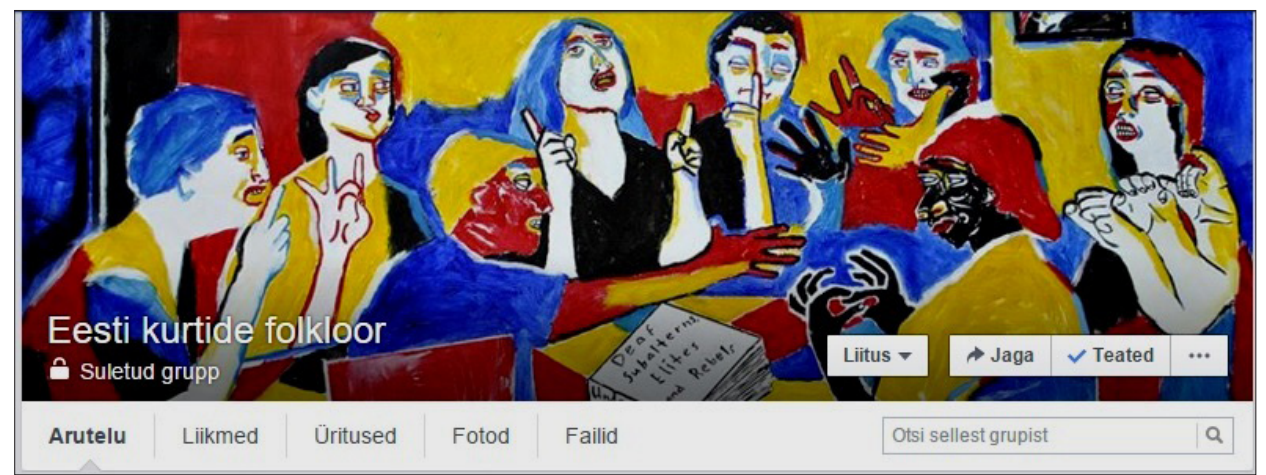

Joonis 3. Facebooki rühma "Eesti kurtide folkloor" tunnuspilt. ${ }^{25}$

\section{Eesti kurtide folkloori rühm Facebookis}

Uus nähtus eesti kurtide folkloorimaastikul on Facebooki rühm "Eesti kurtide folkloor" (https://www.facebook.com/groups/799046843505837/), mis loodi 2015. aasta 5. märtsil. Rühma loojaks ja initsiaatoriks on Gretel Murd. ${ }^{24}$ Alguses oli rühm avatud, kuid hiljem privaatsussätteid muudeti ja rühm muudeti suletuks. Põhjuseks oli see, et rühmaliikmete postitused muutusid folkloori-teemast mittehuvitatutele nende ajajoonel häirivaks. Käesoleval hetkel (05.04.2016) on rühmaliikmeid 590 ja administraatoreid kolm: kogukonna kurdid liikmed Maret Õun ja Gretel Murd ning siinkirjutaja. Nüüd saab grupiga liituda taotluse põhjal, mille administraatorid aktsepteerivad. Selle grupi kontekstis on rahvaluulekogujaks rühma algatanud ja üleskutse esitanud Gretel Murd.

Ülevaatliku referaadi Eesti kurtide folkloori rühma Facebooki postitustest kirjutas grupi üks liikmeid, eesti viipekeele tõlgi eriala üliõpilane Marju Telliskivi (Telliskivi 2015). See töö tehti õppeaine "Kurtide folkloor" raames. Töös sisalduvad andmed kuni 2015. aasta 29. septembrini tehtud postitustest. Siis oli grupis 532 liiget, videopostitajaid oli kokku 155, neist 95 naist ja 60 meest. Telliskivi sõnul on tegemist "elava" grupiga, mis tähendab, et igaüks saab oma videoid, tekste, fotosid või muid sõnumeid lisada, kuid saab ka kustutada. Samuti ei saa kindel olla, kas postitusi on alati tehtud õige nime all. Telliskivi esitas oma töös ka statistika aktiivsemate postitajate ja publikule meeldinud postituste kohta (Telliskivi 2015).

Rühma asutaja Gretel Murd tegi siinkirjutajale ettepaneku koostada eestikeelne rühma tutvustav tekst, mis on järgmine: 
Eesti kurtide folkloori grupp on mõeldud eelkõige Eestimaa kurtide folkloori ehk rahvaluule tutvustamiseks ja kogumiseks. Muidugi võib siia postitada ka välismaa kurtide folkloori kohta. Samuti leiab siit infot kurtide folkloori teadusliku uurimise kohta Eestis ja välismaal.

Head kurdid! Olge julged viiplema eesti viipekeelseid kurtide nalju, mõistatusi, sõrmendtähestiku mänge, elukogemusi kurdina, lapsepõlve mälestusi, koolimälestusi Porkuni kurtide koolist ja Heleni koolist jne.

Võiksite ka viibelda oma uskumustest (kuuljatel näiteks must kass toob õnnetust, peab sülitama $3 x$ üle vasaku ôla, porgandi söömine on silmadele kasulik, kui astud hommikul parema jalaga voodist välja, tuleb hea päev jne). Aga kurtidel? Kas on kurtidel igapäeva elu tavalisi uskumusi? Mida arvatakse kuulmisest ja kuuljatest? Mida arvatakse ja usutakse oma keelest - eesti viipekeelest?

Kõigest sellest võite jagada oma kogemusi!

Facebooki ajajoon võimaldab fikseerida rühmaliikmete postitusi kuupäeva ja kellaajalise täpsusega. Esimese teavitusvideo postitas 5. märtsil 2015 Gretel Murd. Ta selgitas, mis eesmärgil see grupp sai loodud, kutsus üles liikmeid lisama videotekste oma kogemustest, mälestustest, nalju, mängukirjeldusi, esitama mõistatusi jne. Samuti märgiti, et pole lubatud ebaviisakad või kaaslasi alandavad postitused. Siinkirjutaja jagas rühmaajajoonel kurtide folkloori teoreetilisi kirjutisi, tutvustas kurtide folkloori uurimist maailmas ja eriti kurti folkloristi Simon J. Carmelit. Gretel Murd tegeleb ka videotekstide allalaadimise ja arhiveerimisega, osa sellest materjalist on 2015. aastal antud ka Eesti Rahvaluule Arhiivi.

Viimastel andmetel on postitatud üle 350 videoklipi, nendes hulgas viipekeelseid kogemuslugusid, koolimälestusi, Porkuniga (Porkuni kurtide kooli, kaasõpilaste ja õpetajatega) seotud meenutusi ja infot, anekdoote, viipemänge ja mitmesuguseid muid tekste. Peale selle leidub fotosid, hoiatusi kerjavate libakurtide eest, jagatakse libakurtide kohta meediaväljaannete linke, mitmesuguseid isiklikke kogemusi. Esineb muidugi ka teemavälist materjali.

Lisaks eelkirjeldatud materjalile on huvipakkuvad kurtide ebastandardsed kirjalikud kommentaarid, mis peegeldavad viipekeelsete inimeste kirjaliku eesti keele kasutamist. ${ }^{26}$ Rühmaliikmete postitatud viipetekstid, pildilised ja kirjalikud sõnumid vajaks läbivaatamist ja selekteerimist, sest sugugi kõik ei klassifitseeru rahvaluuleaineseks. Laekunud on ka ilmselgelt folklooriväliseid postitusi, mis suunab mõttele, et ehk oleks vaja kurtidele luua muidki videopostitusi võimaldavaid temaatilisi lehekülgi. Mõnda postitust on peetud solvavaks. Administraatorina on tulnud rühma tagasisidet arvestades mõni postitus kustutada. 
Folkloorsed leiud tuleks alla laadida ja arhiveerida edasise säilitamise ja uurimise tarbeks. Nimetatud protseduurid vajavad spetsiaalse ettevalmistusega (olgu siis kuuljaid või kurte) keelevaldajaid, kellel on teadmisi rahvaluulest. Vajadusel tuleks töösse kaasata viipekeeletõlk. Grupi "Eesti kurtide folkloor" videotekstid osutuvad heaks õppematerjaliks ka eesti viipekeele tõlgi eriala tudengitele, tutvumaks eesti viipekeele idiolektidega: eri kurtide individuaalse keelekasutusega.

Siiski tuleb eelkirjeldatud grupi miinusena märkida liikmelisuse piiratust Facebooki kogukonnaga. Rühmaga on liitunud seni peamiselt nooremad ja keskealised inimesed, kes kasutavad sotsiaalmeediat. Eakamaid kurte tuleks jätkuvalt personaalselt külastada, intervjueerida ja salvestada. Siiski on niisuguse kurtide folkloori kogumisruumi tekitamine sotsiaalmeedias kahtlemata pretsedent, millega seostuvad nii kogumisspetsiifilised, eetilised kui ka õiguslikud küsimused. Näiteks kuidas vormistada postitaja nõusolek materjali arhiveerimiseks, avaldamiseks ja edaspidiseks kasutamiseks uurimistöös. Viipekeelse pärimuse kogumiseks ei ole meil veel selgepiirilist praktikat välja kujunenud. Eesti viipekeel kui visuaalne keel on autentsetes videosalvestatud pärimustekstides lahutamatult seotud viiplejaga ehk inimese kujutamisega. Eelkirjeldatud grupi puhul on märkimisväärne see, et esmakordselt nihkus aktiivsuskese kurtide kogukonnale endale. Ka ei ole alati selge, millised postitused haakuksid grupi "Eesti kurtide folkloor" eesmärkidega.

\section{Folkloristika tulevikuväljavaated kuulmisvõimetuse uurimisel}

Tänapäeval on suurepärased võimalused viipekeelse folkloori kogumiseks, säilitamiseks ja esitlemiseks just tänu mitmekesistele tehnoloogilisele vahenditele ja virtuaalsetele keskkondadele. Sotsiaalmeedia on üks võimalikke kogumisruume. Internetis tervikuna leidub rikkalikult eri viipekeeltes kurtide folkloori videotekste, samuti kirjalikke tõlkeid viipekeeltest suulistesse keeltesse.

Kurdid kasutavad visuaalseid kommunikatsioonitehnoloogiaid viipekeelseks kaugsuhtluseks. Eesti viipekeel kui visuaal-motoorne keel on avalik keel: kommunikatsiooni toimumiseks peavad vestluspartnerid teineteist nägema. Oma sõnumi jagamiseks kasutatakse videopostitust, mis võimaldab ajalist nihet ja on võrreldav kirjaliku tekstiga ehkki viipekeeltel muidu kirjalikku kuju pole. ${ }^{27}$ Samas ei ole sugugi kõik tehnoloogilised uuendused - vähemalt esialgu - heakskiitu leidnud. Nii näiteks on kurtide rahvarühmas negatiivset vastukaja leidnud meditsiiniimeks peetav sisekõrva implantaat. Nimelt tajub osa viipekeelseid inimesi ulatuslikku implanteerimist rünnakuna kurtide kultuuri ja viipekeele 
vastu. Vastuseis on kujunenud ilmselt mitmesugustel põhjustel, mille käsitlemist kahjuks käesoleva artikli piiratud maht ei võimalda. Nimetada võiks ehk paternalistlikku suhtumist kurtidesse, kuuljate ja kurtide vahelist kasinat dialoogi, kurtide haridustaset, kuuljate kohati ikka veel alavääristavat suhtumist viipekeelde ja viipekeelsena ligipääsu piiratust ühiskonnaelu eri sfääridesse. Just seetõttu on tekkinud vastavasisuline antifolkloor, mida tuleks talletada. ${ }^{28}$

Just folkloristika pakub avaraid võimalusi kuulmisvõime ja -võimetuse, sealhulgas kurtide rahvarühma, implanteerimise ja ka küberkuuljate käsitlemiseks. Kogumist vajaks implantaadivastane folkloor (kogemusjutud, anekdoodid, meemid, argiarvamused), implanteeritute kogemuslood, visuaalse ja kuuldetehnikaga seotud argiarvamused ja mitmed muud teemad.

Kindlasti aitab kurtide folkloori kogumine, uurimine ja populariseerimine kaasa eesti viipekeele säilitamisele (viipekeelsete allikate loomine), arendamisele ja rikastamisele, kurtide kultuuri hoidmisele ja selle esindajate eneseteadvuse tugevdamisele kuulvas ühiskonnas. Siia liituksid ka küberkuuljate kogemuslood ja kuulmismeelega seotud folkloor laiemalt, mis võimaldaks kuulmisvõimetusega seotud kogemuste laiapõhjalisemat käsitlust.

\section{Kokkuvõte}

Kuulmisvõimetusega (ka kurtuse, kuulmislanguse, kuulmispuudega) seotud teemad on valdkondadevahelised ja nendega on tegeldud loomulikult arstiteaduse ja eripedagoogika, aga ka õigusteaduse, keeleteaduse ja psühholoogia raames. Kõigil neil erialadel on oma spetsiifilised uurimisaspektid ja -eesmärgid, mis võivad mõneti tunduda üksteisele vastu käivad. Tegelikkuses käsitletakse neis kuulmismeele puudumist erinevatelt alustelt ja seega vaid teatud tahku kuulmise või selle puudumisega seotud reaalsusest - kogu spekter on loomulikult palju laiem.

Rahvaluuleteadusel on mitmekülgne potentsiaal tegelda ühe väikerühma suulise pärimuse ja argikultuuriga. Aga mitte ainult sellega, vaid kuulmisvõimetuse kogemusväljaga avaramalt. Folkloristile on viipekeelsed kogemuslood uutest kommunikatsioonitehnoloogiatest, veebipõhisest suhtlemisest, argiarvamused implantaadist ja muust kuuldetehnikast ning nende vastane folkloor, lood ja argiarvamused viipekeeletõlkidest, mis muidu jääksid tähelepanuta, tänuväärne materjal. Vaateväljast ei tohiks kõrvale jääda ka veebis leviv kurdiksolemise teemat käsitlev pildiline folkloor. Kurtide kunstipärase kommunikatsiooni ja kuulmisvõimetuse kultuuriliseks tõlgendamiseks on tarvis tunda kuulmismeelega seotud meditsiinilisi, ajaloolisi, pedagoogilisi, keelelis-kultuurilisi, õiguslikke, sotsiaalpoliitilisi ja muid kontekste. Kurtide folklooritekste saab 
rakendada näiteks uurimistöös, folkloristide ja viipekeeletõlkide väljaõppes, aga kindlasti on veel teisigi väljundeid.

\section{Kommentaarid}

1 Näiteks Euroopa rahvastikul põhjustab kõige sagedamini pärilikku kuulmislangust geenimutatsioon 35delG. Eestis uuriti 113 isikut ja leiti, et mutatsiooni 35delG kandjate sagedus $1: 22,5$ on meil võrreldes Lõuna-Euroopa keskmise sagedusega $1: 35$ ning Kesk- ja Põhja-Euroopa keskmise sagedusega 1 : 79 Euroopa rahvaste seas suurim (Teek et al. 2007: 256).

${ }^{2}$ Küborgiseerimiseks nimetatakse kuulmisvõimetuse kontekstis sisekõrva implanteerimist (Valente 2011). Laiemalt mõeldakse aga selle praktika all inimese ja masina kooslust üldse. Tuntuim küborgite (ingl k cyborg) käsitleja on Donna Haraway, kes kirjutas oma tuntud essee "A Cyborg Manifesto" juba 1980. aastate alguses (Haraway 1985).

3 Viipekeeletõlk on tõlk, kelle üheks aktiivseks töökeeleks on viipekeel või rahvusvaheline viiplemine. Kutseline viipekeeletõlk on viipekeeletõlk, kellele on riiklikult määratud korras omistatud viipekeeletõlgi kutsetase (Kutsekoda: Lisa 1: Viipekeele tõlgi kutsestandardis kasutatud terminite süsteem, http://www.kutsekoda. ee/et/kutseregister/kutsestandardid/10471051/lisad/10471052/lisa-1-kss-kasutatudterminite-susteempdf - 13.06.2016).

4 A. Dundes leiab, et binaarne opositsioon on universaalne. Sellele viitavad kultuuriülesed eristused nii minevikus kui ka olevikus: mehed-naised, elu-surm, öö-päev (tumehele) (Dundes 2002: 150). Käesolevas artiklis on sellisteks opositsioonideks kurdid ja kuuljad, suuline keel ja viipekeel, patoloogia ja mitmekesisus, kuulmisvõimetus ja kurtus või kuulmine.

${ }^{5}$ Kultuuriteadustes kasutatava mõiste kurtus (deafness) kõrvale kerkis 1993. aastal mõiste kurdiksolemine (deafhood). Selle looja, Briti kurdi kultuuriuurija Paddy Laddi järgi on kurtus staatiline meditsiiniline seisund, aga kurdiksolemine protsess ja võitlus. Kurdiksolemisega teadvustab iga kurt laps, kurtide pere ja kurt täiskasvanu endale ja kaasinimestele oma olemasolu (Ladd 2003: 3).

6 Näiteks: kurdid on vaimselt vähevõimekad, nad ei tule eluga toime, nad on meisterlikud suultlugejad, kurdid ei oska nautida kultuuri jmt (Paales \& Paabo \& Reilson 2015: 218-220).

7 Alan Dundes oli Susan D. Rutherfordi 1988. aastal California Berkeley ülikoolis kaitstud ameerika kurtide folkloori alase doktoritöö juhendaja. Väitekiri ilmus trükis 1993. aastal (Rutherford 1993).

8 Suuline meetod (nimetatud ka saksa meetodiks) on kurtide õpetamisviis, milles käelised elemendid on välistatud.

9 Boston university. Deaf Literature and ASL, http://www.bu.edu/academics/sed/courses/ sed-de-551/(13.06.2016). Deaf Literature, http://www.csun.edu/catalog/academics/deaf/ courses/deaf-402/ (13.06.2016).

Deaf Literature and ASL Folklore. Bristol Community College, http://www.mco.mass. edu/includes/courseDetails.jsp?courseId=2607\&courseBrokerInd=N (13.06.2016). 
${ }^{10}$ Eesti viipekeele õpetamine algas Tartu Ülikooli eripedagoogika osakonnas 1990. aastatel, kusjuures kurtide suhtlusviisi ei nimetatud siis veel keeleks.

${ }^{11}$ Simon J. Carmel (snd 1938) on Ameerika kurt folklorist ja antropoloog. Kuuljate vanemate lapsena oli ta emakeeleks inglise keel. Alles Gallaudet' ülikoolis õppis ta selgeks ameerika viipekeele. Carmel on ameerika kurtide folkloori ja kultuuri käsitlevate arvukate kirjutiste autor. Lisaks teadustööle on ta olnud mitmekülgne sportlane ja harrastusmustkunstnik. Ta on koostanud nt Ameerika kurtide mustkunstnike elulugude kogumiku (Carmel 2008).

${ }^{12}$ Viipetekstide valmimist on toetanud Euroopa Sotsiaalfond alameetme "Kõrgkoolide ja ettevõtete koostöö" projektist "Õppekava Eesti viipekeele tõlk arendamine, juurutamine ja jätkusuutlikkuse tagamine". Olemas on järgmised videotekstid: 1) mõistatused Kuidas saada kurti vs kuuljat last (EFA I, 47, 113), Miks on kurdi käsivarrel sinikad (EFA I, 47, 110), Miks on kurdil miimikakortsud (EFA I, 47, 110); 2) jutud Kurdid jahimehed (EFA I, 47, 103), Kurdid kosmoses (EFA I, 47, 98), Kurt koer (EFA I, 47, 98-99), Kurt lõvi (EFA I, 47, 103), Kurt, pime ja liikumispuudega inimene (EFA I, 47, 101), Kurt, pime ja vaegkuulja (EFA I, 47, 99), Kurt pull (EFA I, 47, 103), Kurt puu (EFA I, 47, 100), Kümme musträstast (Carmel 1996: 199), Porkuni kohapärimus (EFA I, 47, 95, 97-98) (5 teksti); 3) uskumused (argiarvamused) (EFA I, 47, 108/119) (3 teksti). Videomaterjalides viiplesid Aivo Erm, Argo Purv ja Maret Oun. Filmis Kert Kalvik ja montaaži tegi Liivi Liiholm (Hollman).

${ }^{13}$ Vaata õppekava "Eesti viipekeele tõlk" TÜ õppeinfosüsteemist https://www.is.ut.ee/ pls/ois/!tere.tulemast (13.06.2016).

${ }^{14}$ Varem oli vastav institutsioon TÜ keeltekeskus - üks institutsioone, mille baasil loodi 2015. aastal Tartu Ülikooli maailma keelte ja kultuuride kolledž. Eesti viipekeele kursuste kohta leidub info http://www.maailmakeeled.ut.ee/et/keelekursused/eestiviipekeel (13.06.2016).

${ }^{15}$ Rahvaluule alaste eesti viipekeelsete mõistete videofailide valmimist on toetanud Euroopa Sotsiaalfond alameetme "Kõrgkoolide ja ettevõtete koostöö" projektist "Õppekava Eesti viipekeele tõlk arendamine, juurutamine ja jätkusuutlikkuse tagamine". Mõistete videofailid viiples Maret Õun, ja need on nähtavad käesoleva artikli võrguversioonis.

${ }^{16}$ Viibete vasted suulises keeles on esitatud versaalis glossina.

${ }^{17}$ Kuna eesti viipekeeles vastavat viibet pole, siis laenati LSF viibe (langue des signes française - prantsuse viipekeel). Suupilt on motiveeritud eesti keelest - etnoloogia. Prantsuse etnoloog Yves Delaporte'i andmetel lõi nimetatud viipe prantsuse kurt ajaloolane Bernard Truffaut. See on kahekäe viibe, milles passiivne käsi osutab rühmale ja domineeriva käe liigutus on motiveeritud viipest CHERCHER / RESERCHER / CHERCHEUR (uurimine, uurija), osutades just rühma uurimisele (Delaporte 2007: 53-54).

${ }^{18}$ ASL (American Sign Language - ameerika viipekeel) viibe. Suupilt on motiveeritud eesti keelest - "folkloor".

19 Kahekäeviibe.

${ }^{20}$ Suuga artikuleeritakse sõna "märk".

${ }^{21}$ Viibe artikuleeritakse suu juures.

${ }^{22}$ Viibe artikuleeritakse rindkere ees.

${ }^{23}$ Mõistefaili subtiitris kirjutatud isikuviibe. 
${ }^{24}$ Gretel Murd oli esimene kurt üliõpilane, kes lõpetas TÜ eesti viipekeele tõlgi õppekava 2015. aastal (vt ka Säde 2015). Ôpingutel läbis ta ainekursuse "Kurtide folkloor" ja sai sellest inspiratsiooni ja innustust. Olles ise kurt, kelle emakeel on eesti viipekeel, võttis ta südameasjaks oma kogukonna pärimuse kogumise. Gretel on esinenud kurtide folkloori tutvustavate ettekannetega näiteks Horvaatias ja Sloveenias.

${ }^{25}$ Kaanepildi valis Gretel Murd ja see on leitud Google’i pildiotsinguga. Õlimaali "Kurtide kultuuri mõistmine" autor on Ameerika kurt kunstnik Nancy Rourke, kelle loomingu aluseks on kurdiksolemise kogemus ja ameerika viipekeel. Maalil on näha suure lambi valguses ümber laua istumas kurtide rühma. Nad arutlevad briti kurdi teadlase Paddy Ladd'i raamatu "Understanding Deaf Culture: In Search of Deafhood" üle. Laua all on kurt koer, kelle kaelarihmale on kirjutatud Kurt koer, oskan ASLi. Seinal on tuntud prantsuse kurdi õpetaja Laurent Clerc'i pilt (Deafhood Art: Understanding Deaf Culture).

${ }^{26}$ Näiteks pärast rühma avamist postitas üks liige 05.03.2015 ajajoonele järgmise sõnumi: Hea idee! Siis kurtide ei tee igavaks ;) (Y). Kuuljale võib kirjutatu jääda üsna mõistetamatuks või vähemalt kummaliseks. Teksti pisut korrigeerides tähendab see, et sellise rühma loomine on hea idee ning selle olemasolu muudab kurtide elu huvitavamaks ja peletab igavust.

${ }^{27}$ Videosalvestist loetakse tänapäeval viipekeelte kontekstis kirjalikuks tekstiks.

${ }^{28}$ Antifolkloori näitena toodud järgnev tekst on autoripoolne ümberjutustus ameerika viipekeelsest, silmnähtavalt iroonilisest lühifilmist, kus figureerib kurt koomik Tom Neville. On aasta 2012. Analoogselt McDonalds'i kiirtoitlustusega on levinud ka implanteerimiskett McImplant. McImplanti sõidavad autodega nii kurdid üksikisikud kui ka terved kurtide pered. Soovijad saavad endale valida kas ühe-või kahepoolse implantaadi, superimplantaadi, soovitud värvitoonis implantaadi jne. Implanteerimine toimub kiirkorras konveiermeetodil: ühest aknast edastatakse implantaadi tellimussoov, teise akna kaudu täidetakse tellimus. Toiminguks peab kurt isik omama tervisekindlustust. Implantaadi toimimist demonstreeritakse autoraadio ja linnulaulu kuulmisega. Kui kurtidel on pretensioone - nt paigaldati neile teist värvi seade, kui oli soovitud või opereeriti implantaat valesse kõrva, siis korrigeeritakse tehtud vead. Lugu lõpeb klienditeenindaja pöördumisega: "Kui soovite kuuljaks saada, siis pöörduge meie poole.” Tiitrina jookseb kiri: McImplant. Üle 500 miljoni teenindatu. (Deaf McImplant 2007).

\section{Allikad}

\section{Arhiivimaterjalid}

EFA I 47 = Eesti viipekeelne pärimus. EFA I 47, 93/120. Eesti Kirjandusmuuseumi rahvaluule arhiiv. Käsikirja koopia autori valduses.

\section{Veebilehed ja veebisõnastikud}

Deafhood Art: Understanding Deaf Culture. Nancy Rourke Paintings (http://www. nancyrourke.com/understandingdeafculture.htm - 26. september 2016). 
Eesti kurtide folkloor. Facebook (https://www.facebook.com/groups/799046843505837/?fref=ts26. september 2016).

Eesti Statistikaamet. Statistika andmebaas. Rahvastik: RL0431: Rahvastik emakeele ja soo järgi, 31. detsember 2011 (http://pub.stat.ee/px-web.2001/Dialog/varval. asp?ma=RL0431\&lang=2 -26 . september 2016).

Eesti viipekeele - eesti keele sõnastik. Eesti Keele Instituudi kodulehekülg (http://www. eki.ee/dict/viipekeel/ - 13. juuni 2016).

Eesti viipekeel. Tartu Ülikooli kodulehekülg (http://www.maailmakeeled.ut.ee/et/ keelekursused/eesti-viipekeel - 26. september 2016).

Kutsekoda. Lisa 1. Viipekeeletõlgi kutsestandardis kasutatud terminite süsteem (http:// www.kutsekoda.ee/et/kutseregister/kutsestandardid/10471051/lisad/10471052/lisa-1kss-kasutatud-terminite-susteempdf - 26. september 2016).

Deaf McImplant 2007. Deafridge Production. ASL Media, LLC (http://www.youtube. com/watch?v=R7vhhzoyz9s - 26. september 2014).

Rahvusvahelise viiplemise e-sõnastik (http://rv-sonastik.ead.ee/ - 26. september 2016).

Spread the sign: Sign Language Dictionary (https://www.spreadthesign.com/ 26. september 2016).

\section{Kirjandus}

Batterbury, Sarah C. E. \& Ladd, Paddy \& Gulliver, Mike 2007. Sign Language Peoples as Indigenous Minorities: Implications for Research and Policy. Environment and Planning 39, lk 2899-2915.

Carmel, Simon J. 1996. Deaf Folklore. Brunvand, Jan H. (toim). American Folklore: An Encyclopedia. Garland reference library of the humanities 1551. New York \& London: Garland Publishing, Inc., lk 197-200.

Carmel, Simon J. 2008. Silent Magic: Biographies of Deaf Magicians in the United States from the 19th to 21st Centuries. SPS Publications, Inc.

Davis, Lennard D. 2008. Post deafness. Bauman, Hans-Dirksen L. (toim). Open Your Eyes: Deaf Studies Talking. University of Minnesota Press, lk 314-326.

Delaporte, Yves 2002. Les sourds, c'est comme ça. Ethnologie de la surdimutité. Mission du Patrimoine ethnologique. Collection Ethnologie de la France 23. Paris: Éditions de la Maison des Sciences de l'Homme.

Delaporte, Yves 2007. Comment traduire "ethnologie" en langue des signes? Le Journal de l'AFILS 64, lk 53-54.

Dundes, Alan 2002. Kes on rahvas? Valik esseid folkloristikast. Tallinn: Varrak.

Eckert, Richard Clarc 2010. Toward a Theory of Deaf Ethnos: Deafnicity $\approx D /$ deaf (Hómaemon. Homóglosson. Homóthreskon). Journal of Deaf Studies and Deaf Education 15 (4), lk 317-333 (http://jdsde.oxfordjournals.org/content/15/4/317.full.pdf+html 26. september 2016). 
Haraway, Donna 1985. A Manifesto for Cyborgs: Science, Technology, and Socialist Feminism in the 1980s. Socialist Review 15: 2, lk 65-108 (doi: 10.1080/08164649.1987.9961538).

Ladd, Paddy 2003. Understanding Deaf Culture: In Search of Deafhood. Clevedon, Buffalo, Toronto, Sydney: Multilingual Matters.

Laiapea, Vahur \& Miljan, Merilin \& Sutrop, Urmas \& Toom, Regina 2003. Eesti viipekeel. Tallinn: Eesti Keele Sihtasutus.

Matthews, Philip W. \& McKee, Rachel L. \& McKee, David 2009. Signed Languages, Linguistic Rights and the Standardization of Geographical Names. Proceedings of the 23rd International Congress of Onomastic Sciences. York University, lk 721-732 (http:// yorkspace.library.yorku.ca/xmlui/handle/10315/4011 - 26. september 2016).

Paabo, Regina 2010. Viibelda on mõnus. Käsiraamat eesti viipekeele õppimiseks. Töid antropoloogilise ja etnolingvistika vallast 3. Tallinn: Eesti Keele Sihtasutus.

Paabo, Regina 2011. Eesti viipekeele aabits. Tartu: Studium.

Paales, Liina 2000. Eesti kurdipärimuse piirjooni maailma kurdipärimuse ja rahvaluuleteaduse taustal. Magistritöö. Tartu: Tartu Ülikool. Käsikiri eesti ja võrdleva rahvaluule osakonnas.

Paales, Liina 2001. Kas viipekeeles saab laulda - ehk kurdipärimuse liikidest eesti viipekeelse rahvaluule näitel. Hiiemäe, Mall \& Labi, Kanni (koost). Klaasmäel. Pro folkloristica VIII. Tartu: Eesti Kirjandusmuuseum, lk 129-148.

Paales, Liina 2011. Kurtide nimepärimuseaspekte: puudelisuse ja kurdiksolemise folkloristlik uurimus. Dissertationes folkloristicae Universitatis Tartuensis 17. Tartu: Tartu Ülikool (http://dspace.ut.ee/bitstream/handle/10062/18183/paales_liina. pdf?sequence=3\&isAllowed=y -26 . september 2016).

Paales, Liina \& Paabo, Harri \& Reilson, Mari 2015. VI Viipekeeletõlgi klientuur. Paabo, Regina (toim). Viipekeeletõlgi erialaõpik. Tartu: Tartu Ülikool, lk 193-229. Käsikiri artikli autori valduses.

Rutherford, Susan Dell 1993. A Study of American Deaf Folklore. Linstok Press Dissertation Series. Linstok Press, Inc.

Säde, Merilyn 2015. Gretel Murd: kurdid ei peaks kartma ülikoolis õppimist. Universitas Tartuensis. Tartu ülikooli ajakiri (http://www.ajakiri.ut.ee/artikkel/1471 - 26. september 2016).

Teek, Rita \& Raukas, Elve \& Oitmaa, Eneli \& Joost, Kairit \& Kruustük, Katrin \& Žordania, Riina 2007. Pärilik ehk geneetiline kuulmislangus. Eesti Arst 86 (4), lk 254-261 (http://ojs.utlib.ee/index.php/EA/article/viewFile/10182/5369 - 26. september 2016).

Telliskivi, Marju 2015. Facebooki grupp Eesti kurtide folkloor postitused. Referaat. Tartu: Tartu Ülikool, Haridusteaduste instituut. Käsikiri artikli autori valduses.

Toom, Regina 2002. Viipekeeletôlkide professionaalne areng Eestis. Magistritöö. Tartu: Tartu Ülikool. Käsikiri Tartu Ülikooli raamatukogus

Uhlig, Anne C. 2012. Ethnographie der Gehörlosen. Kultur - Kommunikation Gemeinschaft. Bielfeld: transcript. 
Valente, Joseph Michael 2011. Cyborgization: Deaf Education for Young Children in the Cochlear Implantation Era. Qualitative Inquiry, September, 17 (7), lk 639-652 (doi: 10.1177/1077800411414006).

\section{Summary}

\section{Collecting, studying, and teaching Deaf folklore}

\section{Liina Paales}

Keywords: Deafhood, Deaf folklore, Estonian Deaf community, Estonian Sign Language, Facebook, folklore

Different aspects of deafness are dealt with within the realms of, for example, medicine, law, educational science, and psychology. This article focuses on the Deaf folk group, and more specifically on the Estonian Deaf community and its culture from the viewpoint of folkloristics. The article views the possibilities of folklore research in studying deafness and Deafhood and in the application of such information.

This article springs from the approach of the American folklorist Alan Dundes on folk groups. The term 'folk group' enables to be unspecific about whether the group is a minority, ethnos, disability, or any other type of group. For Deaf group identity, different manifestations of similarity are considered, like, for example, Deafhood, sign language skills, and knowledge of Deaf culture.

In Estonia the number of Deaf community members is approximately 1300 . The Estonian Sign Language is estimated to have about 4500 regular deaf and hearing users. In Estonia, 1-2 deaf babies are born for every 1000 children, approximately 15 children per year. Most of the deaf children are born into hearing families; they are switched into the cyborgization process and go to regular schools. From the cultural point of view, such deaf children grow into hearing people.

The Estonian Sign Language started to be taught at the University of Tartu in the 1990s. The author, who is a hearing person, started collecting and studying Estonian Deaf folklore in the middle of the 1990s. The subject course in Deaf folklore was first taught at the University of Tartu in the 2007/2008 academic year under the curriculum Estonian Sign Language interpreter. In order to describe Deaf folklore, it was necessary to create terminology in Estonian and in the Estonian Sign Language. For the purpose of the Deaf folklore course, video files and folklore texts of folklore terms in the Estonian Sign Language were recorded in cooperation with Deaf people.

A new environment for collecting Estonian Deaf folklore is the Facebook group Eesti kurtide folkloor (Estonian Deaf folklore), which can be joined by sending a request. This group was formed by Deaf interpreter Gretel Murd on 5/03/2015. The group has more than 500 deaf and hearing members and three administrators (two deaf and one hearing). Its members have posted videos, shared photos and written texts in Estonian. Video texts contain, for example, jokes, sign play, riddles, memories from the school for the Deaf, and experience stories. 
Unfortunately, the group is limited to the Facebook community. So far, mostly younger and middle-aged people who use the social media have joined the group. Elderly Deaf people should still be visited personally, interviewed, and recorded. Yet, creating such a space for collecting Estonian Deaf folklore is undoubtedly a precedent, which involves collection-specific as well as ethical and legal issues. Its positive aspect is that for the first time the centre of activity in collecting group lore was shifted to the Deaf themselves.

Folkloristics offers plenty of opportunities for discussing the topics of hearing ability and Deafhood, including the Deaf folk group, implantation, and cyber-hearing people (cyborgs). Anti-folklore concerning cochlear implants (experience stories, jokes, photos, cartoons), experience stories of those having implants, everyday opinions on visual and audio equipment, and various other topics are still waiting to be collected.

Collecting, studying, and promoting Deaf folklore contributes to the preservation, development, and enrichment of the Estonian Sign Language, maintaining the Deaf culture and enhancing the self-concept of its representatives in the hearing society. Folklore texts communicated by deaf people in sign language are suitable as authentic sign-language sources for study materials both in the training of the Estonian Sign Language interpreters and folklorists, as well as for studying Deaf folklore and the Estonian Sign Language. 